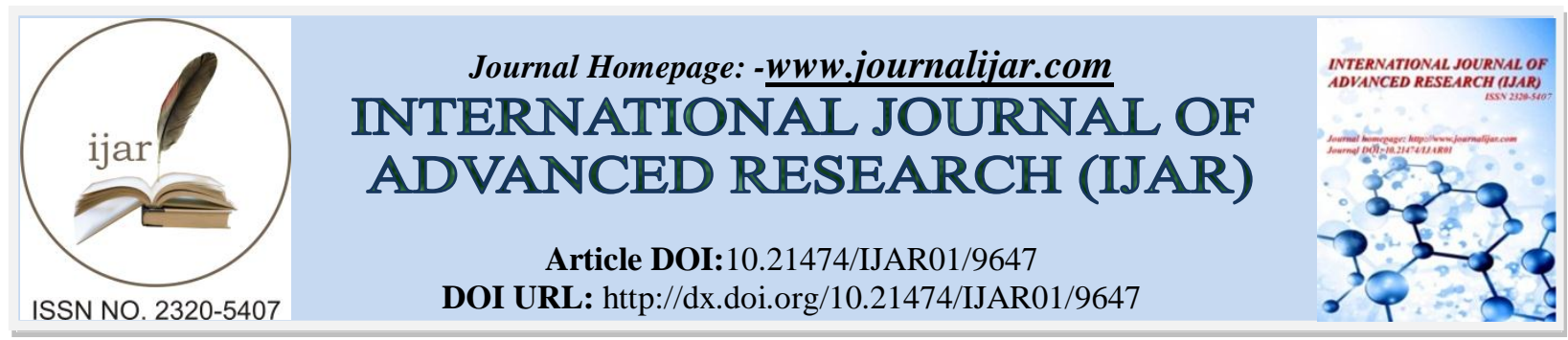

RESEARCH ARTICLE

\title{
STUDY ON PRESCRIPTION PATTERN OF ANTI HYPERTENSIVE'S IN PATIENTS OF PREGNANCY INDUCED HYPERTENSION AT TERTIARY CARE HOSPITAL.
}

\author{
Dr.Shruti Gupta ${ }^{1}$, Mr.CH.Nagesh ${ }^{2}$ and Dr. Ambrish Gupta ${ }^{3}$. \\ 1. Assistant Professor in Department of Obstetrics\&Gynaecology, G.S.V.M Medical College, Kanpur. \\ 2. Lecturer in Department of Pharmacology, Government Medical College, Kannauj. \\ 3. Professor in Department of Pharmacology, Government Medical College, Kannauj.
}

\section{Manuscript Info}

Manuscript History

Received: 04 July 2019

Final Accepted: 06 August 2019

Published: September 2019

Key words:-

Pregnancy Induced Hypertension (PIH),

Methyldopa, Labetalol.

\begin{abstract}
Introduction: During pregnancy, Hypertension has become the most common medical problem and it is also remains main cause of maternal and fetal morbidity and mortality. It complicates almost $10 \%$ of all pregnancies.

Aim: Present study was conducted to evaluate the prescribing pattern in pregnancy induced hypertension.

Methods:A cross sectional study was carried out by evaluating prescription of 110 pregnant womens, who had diagnosed with PIH in Department of Pharmacology in collaboration with Department of Gynecology and Obstetrics. The data was analyzed by using SPSS software and results were expressed in percentage.

Results: A Total of 110 Prescriptions were collected, among them, 56\% of womens were diagnosed with stage-II hypertension (B.P $\geq 160 / \geq 100$ ) and rest were diagnosed stage-I. In this, $77.2 \%$ of cases had received a single antihypertensive drug, while $18.1 \%$ had received two antihypertensive drugs\& $4.5 \%$ received triple drugs therapy.

Methyldopa was given in 35 patients (i.e. $31.8 \%$. cases) as monotherapy and followed by Labetalol in 27 patients ( $24.5 \%$.cases). Combination of methyldopa and labetalol was the most common dual antihypertensive regimen given in $11.8 \%$ of cases.

Conclusion: During treatment with antihypertensive agents, prescriber should be very cautious as they are having history of causing foetal abnormality. Our study concluded that incidence of PIH is high and Methyldopa was the commonest drug given either alone or in combination therapy, as it is a safest during pregnancy. Patients also received other drugs for various purposes like, calcium supplements, iron, folic acid and multivitamin
\end{abstract}

Copy Right, IJAR, 2019,. All rights reserved.

\section{Introduction:-}

Hypertension had become one of the most common disorders in pregnancy. Hypertensive disorders of pregnancy are considered to be a major worldwide health problem running an increased risk of Perinatal and maternal mortality ${ }^{1}$ Pregnancy induced hypertension can be said only, when systolic blood pressure (sBP) increased $\geq 30 \mathrm{mmHg}$, or diastolic blood pressure increased(d BP) $\geq 15 \mathrm{mmHg}$ from preconception or first trimester blood pressure. However 
it can be confirmed only after 2 measuring with 6 hours of gap. ${ }^{2}$ The incidence of pregnancy induced hypertension in India is about $7-10 \%$ of all antenatal admission ${ }^{3}$. There are so many factors associated in developing preeclampsia which are type one diabetes, gestational diabetes, twin's birth and obesity (Body mass index $>29)^{4}$.

Prescriber should be so cautious while prescribing medication to pregnant women as rational drug use in pregnancy requires balance between benefit and risks associated with drug usage 5 .A number of drugs in various combinations are generally used for effective long -term management of hypertension. But only few drugs are prescribed in pregnancy induced hypertension due to their adverse events in mother and fetus.

\section{Materials\&Methods:-}

This is a cross sectional study, which was carried out by evaluating prescriptions of 110 subjects who had definite diagnosis of pregnancy induced hypertension in Department of Obstetrics, G.S.V.M Medical college, Kanpur \& in collaboration with pharmacology Department, Government Medical College, Kannauj, from May to June, 2019.

\section{Inclusion Criteria}

Prescriptions were collected from patients after being diagnosed with pregnancy induced with hypertension.

\section{Exclusion criteria}

Patients of preexisting hypertension, not willing to give their informed consent, with comorbidity and were taking medicines for other clinical problems were excluded.

Patient's details such as name, age, complaints, investigations, treatment details were collected. The data was analyzed by using SPSS software and results were expressed as percentages.

\section{Results:-}

There were three subset of age groups in which PIH is most common (53.6\%) in age group between 20 to 25 years followed by $25.4 \%$ in age group between 26 to 30 years and between 31 to 35 years of age group we found $20.9 \%$ of women with PIH.Table-1

The incidence of hypertension was high in among Primigravida(Table-2).77.2\% of the patients received single antihypertensive agent, $18.1 \%$ received two drugs and three drugs were given in $4.5 \%$ of patients.( Table-3) All the drugs were prescribed in generic names and in Capital letters of English and all the prescriptions were signed by the prescriber.

Methyldopa was prescribed in $31.8 \%$ of patients as mono therapy, $18.1 \%$ of patients received as dual therapy and in $4.5 \%$ of patients given as triple therapy. Methyldopa was the most common drug given in $54.4 \%$ of patients either alone or in combination with other drugs. Labetalol was given in $24.5 \%, 11.8 \%$, and $4.5 \%$ of patients as mono, dual\& triple therapy respectively. Third most common drug was nifedipine, given in $16.3 \%$ of patients as monotherapy, $6.3 \%$ of patients were received as dual therapy and in $4.5 \%$ patients given as triple therapy. Another antihypertensive was Hydralazine, given in $4.5 \%$ of patients as monotherapy\& it was the least common drug prescribed.(Table-4).

Table1:-Demographic distribution of the patients

\begin{tabular}{|c|c|c|}
\hline Age groups & No of Patients(n=110) & Percentage (\%) \\
\hline $20-25$ & 59 & $53.6 \%$ \\
\hline $26-30$ & 28 & $25.4 \%$ \\
\hline $31-35$ & 23 & $20.9 \%$ \\
\hline
\end{tabular}

Table 2:-Gravidity wise distribution of patients

\begin{tabular}{|c|c|c|}
\hline Gravida & No. of patients $(\mathbf{n}=\mathbf{1 1 0})$ & Percentage (\%) \\
\hline Primigravida & $\mathbf{6 9}$ & $\mathbf{6 2 . 7 \%}$ \\
\hline Multigravida & 41 & $\mathbf{3 7 . 2 \%}$ \\
\hline
\end{tabular}


Table3:-Prescribing pattern of drugs in hospital

\begin{tabular}{|c|c|c|}
\hline Drug therapy & $\mathbf{n = 1 1 0}$ & Percentage \\
\hline Single drug & 85 & $77.2 \%$ \\
\hline Dual drug & 20 & $18.1 \%$ \\
\hline Triple drug & 5 & $4.5 \%$ \\
\hline
\end{tabular}

Table 4:-Prescribing pattern of antihypertensive's

\begin{tabular}{|c|c|c|c|}
\hline Variables & Drug name & $\mathbf{n = 1 1 0}$ & Percentage (\%) \\
\hline \multirow{3}{*}{ Single Drug Therapy } & Methyldopa & 35 & $31.8 \%$ \\
\cline { 2 - 4 } & Labetalol & 27 & $24.5 \%$ \\
\cline { 2 - 4 } & Nifedipine & 18 & $16.3 \%$ \\
\hline \multirow{2}{*}{ Dual Drug Therapy } & Hydralazine & 5 & $4.5 \%$ \\
\cline { 2 - 4 } & Methyldopa+ Labetalol & 13 & $11.8 \%$ \\
\hline Triple Drug Therapy & Methyldopa+ Nifedipine & 7 & $6.3 \%$ \\
& & 5 & $4.5 \%$ \\
\hline
\end{tabular}

Table 5:-Drug utilization pattern in PIH patients other than antihypertensive agents.

\begin{tabular}{|c|c|c|}
\hline Drug & $\mathbf{n = 1 1 0}$ & Percentage \\
\hline Calcium supplements & 104 & $94 \%$ \\
\hline Multivitamins & 45 & $40.9 \%$ \\
\hline Iron & 53 & $48.1 \%$ \\
\hline Folic acid & 27 & $24.5 \%$ \\
\hline
\end{tabular}

Most commonly prescribed antihypertensive was Methyldopa followed by labetalol and finally Nifedipine as mono therapy or in combination therapy. When it comes to dual drug therapy, combination of Methyldopa +Labetalol was given in $11.8 \%$ of patients and $6.3 \%$ of patients received combination of Methyldopa+ Nifedipine. Combination of Methyldopa + Labetalol+ Nifedipine was given as triple drug therapy in $4.5 \%$ of patients. Table- 4

Besides antihypertensive's, patients also received various drugs for different purposes like, calcium supplements (i.e 94\%) folic acid (i.e 24.5\%) iron (i.e 48.1\%) and multivitamins (i.e 40.9\%) as their demand increases during pregnancy.Table-5

\section{Discussion:-}

Hypertensive disorders of pregnancy are considered to be a major worldwide health problem with increased risk of Perinatal and maternal mortality ${ }^{1}$. According to our study, the incidence of pregnancy induced hypertension was 7.8 $\%$ and which is in range of India's prevalence of pregnancy induced hypertension, i.e. 7 to $10 \%{ }^{3}$. Highest incidence of PIH was found in 20 to 25 years of age group and results are similar to the study conducted by ManjushaSajith et.al $^{6}$, and it may be due to the majority of conceptions take place in this age group in our country.We found highest incidence of PIH in among Primigravida and Almost similar result were found in another studies done by Tanuja VH et.al ${ }^{7}$ and Naveen kumar .T et. $\mathbf{A l}^{8}{ }^{8}$

The most commonly prescribed antihypertensive in this study was Methyldopa (i.e 31.8\%) Labetalol (i.e 24.5\%) followed by Nifedipine (i.e16.3\%) as single drug therapy. Methyldopa is a centrally acting sympatholytic drug. In present study, it is the most commonly prescribed drug either alone or in combination therapy and these results are in similar to the previous studies conducted by ManjushaSajith et.al ${ }^{6}$ and $\mathbf{C v i j i c} \mathbf{M}$ et.al. ${ }^{9}$ Similar study done by Ray JG et.al ${ }^{10}$, but in this study nifedipine was the most commonly prescribed drugthan methyldopa. This shows that prescription pattern is differs from hospital, prescriber among countries also.

Methyldopa is the safest drug and followed by nifedipine but, nifedipine cannot be given as $1^{\text {st }}$ line drug because it can reduce the uterine contractions. When it comes to dual drug therapy, Methyldopa +Labetalol was given in $11.8 \%$ of patients. Similar study done by ManjushaSajithet $\mathbf{a l}^{6}$ but, in their study Methyldopa +Labetalol combination is the second most used combination after methyldopa+ nifedipine. 
Besides ant hypertensive's, patients also received various drugs for different purposes like, calcium supplements (i.e 94\%) folic acid (i.e 24.5\%) iron (i.e 48.1\%) and multivitamins (i.e 40.9\%) as their demand increases during pregnancy.

\section{Conclusion:-}

Early diagnosis and treatment play a major role in prevention of complications of pregnancy induced hypertension. During treatment with antihypertensive agents, prescriber should be very cautious as they are having history of causing foetal abnormality. Our study concluded that incidence of PIH is high and Methyldopa was the commonest drug given either alone or in combination therapy, as it is a safest during pregnancy. Patients also received other drugs for various purposes like, calcium supplements, iron, folic acid and multivitamins.

\section{References:-}

1. Kauntiz A.M, Hughes J.M, Grimes D.H, Smith J.C, Rochat R.W and Kaffrissen M.E. Causes of maternal mortality in the United States of American Journal of Obstetrics and Gynecology 1985; 65:605 - 612.

2. Folic M, Folic N, Varjacic M, Jakovljevic M, Jankovic S. Antihypertensive drug therapy for hypertensive disorders in pregnancy. ActaMedica Medianae.2008;47(3):67-71.

3. National high blood pressure education program working group, report on high blood pressure in Pregnancy. American Journal of Obstetrics and Gynecology 1990; 163: 1691 - 1712

4. Saudan P, Brown MA, Buddle ML et al. Does gestational hypertension become pre-eclampsia. British Journal of Obstetrics and Gynaecology,1998,105(11):1177-84 .

5. Sharma R, Kapoor B, Verma U. drug utilization pattern during pregnancy in North India. Indian J Med Sci. 2006;60(7):277-86.

6. ManjushaSajith, VandanaNimbargi, Amit Modi, RonakSumariya, AtmaramPawar. Incidence of pregnancy induced hypertension and prescription pattern of antihypertensive drugs in pregnancy.IJPSR;5(4):163-170.

7. Tanuja VH, Santosh Kumar J, Manjunath S, Vinod Kumar CS. Drug utilization study of antihypertensives in obstetric practice in a tertiary care hospital. IJACPT. 2010;1(3):1006-10.

8. Naveen Kumar T, Tadvi NA, Kaul R. Prescription pattern of drugs in pregnancy induced hypertension in a tertiary care hospital.IJBCP. 2013 Dec;2(6):783-787.

9. Cvijic M, Horvat M, Jernejcic P, Verdenik I, Geršak K. Analysis of the intake of drugs used in hypertensive disorders during pregnancy. ZdravVestn 2010; 79: 412-18.

10. Ray JG, Vermeulen MJ, Burrows EA, Burrows RF. Use of antihypertensive medications in Pregnancy and the risk of adverse perinatal outcomes: McMaster Outcome Study of Hypertension in Pregnancy 2 (MOS HIP 2). BMC Pregnancy and Childbirth 2001; 1:6. 